\title{
INICIAÇÃo À CIÊNCIA E IMAGINAÇÃo CiENTÍFICA
}

\author{
LUZIA MARTA BELLINI ${ }^{1}$ \\ ADRIANO RODRIGUES RUIZ ${ }^{2}$
}

Bem vindos, amigos, à imaginação científica!!

$\mathrm{O}$ que queremos ao ensinar ciências às crianças $\mathrm{e}$ aos jovens? Por que ensinamos ciências a eles? Seriam perguntas banais se näo tivéssemos ouvindo o eco da saudação de Jorge Wagensberg a biólogos, fisicos e matemáticos no encontro do Museu de Ciências de Barcelona em 1987 para meditar e pensar sobre ciência e filosofia: "Bem vindos, amigos, à imaginação científica!"

Ouvindo sua saudação perguntamo-nos: A escola tem permitido o exercício da imaginação científica entre as crianças e os jovens? Acreditamos que não. Embora esforços sejam feitos por muitos pesquisadores preocupados com a educação para a ciência, esta ainda estâ adormecida nos braços de uma instituição que não mudou sua organização espaço-temporal desde que apareceu em nossa cultura moderna.

A organização escolar traz em seu interior um traçado moderno, o do funcionamento das primeiras fábricas, um legado medieval quando trata da aprendizagem cientifica e uma herança mais antiga ainda que é a da primazia da burocracia em detrimento do corpo de ensino. Estes laços, em nossa visão, amarram a imaginação e a criatividade dos alunos em aulas de

\footnotetext{
${ }^{1}$ Professora Doutora da Untversidade Esladual de Maringá, PR.

${ }^{2}$ Professor Doutor da Universidade Estadual de Maringá, PR.
} 
cinqüenta minutos em salas com carteiras enfileiradas (como nas fábricas). No lugar do estímulo para a capacidade de imaginar, experimentar e criar, a escola cultiva uma passividade mental para o receituário dos livros didáticos e trata as ciências com um ensino de natureza medieval, tornando os alunos meros repetidores de lições dos livros.

$\hat{\mathrm{E}}$ este um empenho para aprender/fazer ciência? O filósofo John Passamore disse que näo. A aprendizagem em ciência nada tem a ver com a rotina, menos ainda com o lugar comum dos livros didáticos. Passamore (apud Sagan, 1996, p.336) chamou nossa atenção quando apontou essa rotina nas instituiçōes de ensino:

Nâo se lêem as obras dos grandes cientistas, nem as contribuiçōes diárias para a literatura científica (...) Ao contrório do humanista iniciante, o cientista iniciante não tem contato com o gênio. Na realidade (...) os cursos escolares podem atrair para a ciência o tipo totalmente errado de pessoa - meninos $e$ meninas que gostam de rotina.

São poucos os estudantes que seguem carreira cientifica, alerta Sagan. Parece que a escola tem apostado na rotina, não motivando, assim, seus jovens a procurar a matemática, a física, a química, a biologia e outras áreas da vida científica. A imaginação nada tem a ver com esse fazer aprisionado no tempo e espaço escolar adornado por livros nada desafiadores ao exercicio intelectual e afetivo. Quando esquecemos ou omitimos a beleza e a criação dos conhecimentos para realçar os chamados conteúdos obrigatôrios e seqüenciais não estaremos, como escreveu Bruno Bethelhein, impedindo que a alma da criança ressoe em comunhäo com os conhecimentos?

Muitos pensadores e cientistas falaram de suas experiências com o mundo natural: Goethe, Kepler, por exemplo. Eles nos deixaram pistas para pensar a iniciação 
às ciências exaltando a beleza do mundo e do pensamento humano.

Imaginação científica e experiência estêtica

Para Kepler que o homem quando cria está pensando objetos de beleza, pensar objetos da natureza é uma experiência estética: o contraste das cores, o canto dos pássaros, o campo gravitacional, o andar de uma centopéia, as flores que se abrem em pencas, os dezessete anos da cigarra Magicinata vividos debaixo da terra antes de sair, crescer, cantar e se reproduzir, as entonaçöes da voz humana são realidades do nosso mundo e são "objetos" de nosso pensar.

O fazer ciência não está separado do exercicio do prazer. O matemático Huntley avisou: "senão para contemplar a beleza da harmonia, não valeria a pena dedicar-se à ciência". Quem não se admira, ao saber que podemos "ver" uma seqüência matemática, a chamada seqüência Fibonacci, em pétalas de flores? Gue podemos "observar" a regularidade do número primo no gênero Magicicata das cigarras que vivem 17 anos sugando pacientemente a raiz das árvores? Ou que a parte interna de um pequeno caracol descreve curvas matemáticas?

Goethe, há mais de um século, falou desse vinculo entre ciência e arte. Ressaltava o papel do OBJETO na ciência: ele faz o cientista pensar e criar, estabelecer relações. Observar os objetos, experimentar, criar relaçōes entre as coisas do mundo são exercícios de nossa inteligência, pois as relaçōes não estão no material, somos nós quem as estabelecemos, nôs as criamos, as imaginamos. Objeto, observação, experimentação são necessidades para nosso pensar o mundo das coisas, são parte da aventura do pensar, como disse Kant.

$\mathrm{Na}$ iniciação à ciência vale resgatar a sensibilidade para aguçar a imaginação dos aprendizes: "A natureza 
ama esconder" disse Herâclito e, talvez, nossos esforços mais fecundos seriam o de dar asas à nossa imaginação para compreender o que a natureza está nos dizendo. Dessa busca de entendimento do que são os fenômenos naturais de nosso mundo faz surgir nosso estilo de pensar. Os objetos ao redor das crianças, seus "olhares curiosos e pensantes" e a imaginação dão os movimentos para a criatividade científica. Se retomarmos a admiração de Goethe na "A Metamorfose das Plantas", de 1798, (Citati, 1996, p. 32), quando descreveu:

\begin{abstract}
(...) cada planta brota da semente e confia aos cuidados da luz $e$ delicadissima estrutura das folhas nascentes; como a folha se expande, se recorta, se divide em partes e pontas; taluda $e$ denteada sobre a superficie intumescida; como se contrai, erguendo sutll e rapidamente o caule e abrindo o cálice pródigo em corolas coloridas e suntuosas, como a flor ondula sobre a ágll armação das folhas mutávets e finalmente se contrai mais uma vez, formando as inúmeras sementes, emaranhadas no regaço materno dos frutos.
\end{abstract}

Talvez o "objeto" natureza as crianças pudessem sair da cultura padrão de pensar ciência. Observar/pensar a cor e a forma das flores de "onze horas" que se abrem coloridas entre 10 horas e meio dia; do girassol girando e nos surpreendendo com a beleza, a harmonia e o desenvolvimento dessas plantas estariamos fugindo da rotina dos bancos escolares e do mundo mecanicista dos livros didáticos. Mais: Não separariamos o cientista do artista pois os aprendizes das ciências comporiam os objetos de nosso mundo, delicadamente traçando os detalhes de seu corpo, sua composição, suas cores. Nesse caminho, por que não pensar os hexágonos tão perfeitos de uma colméia? Seriam as abelhas geômetras? A curva exponencial descrita pelas bactérias em seu crescimento? Como andam as centopéias com tantas patas? 
A aventura do pensar objetos/fenòmenos da natureza é um caminho para a ciência, para o conhecimento e para inteligência.

Goethe falava em "reunir uma seqüência de experiências superiores" para "o entendimento, a imaginação, a perspicácia". O cientista da natureza não pode se desvencilhar dos objetos naturais, nem prescindir das experimentaçōes, pois há uma grande diferença entre uma demonstração matemática e uma demonstração científica na botânica ou com objetos da natureza.

Há duzentos anos atrás, Goethe apontou o espaço qualitativo das operações mentais (que chamou de senso comum), sem dicotomizar objeto e sujeito, sem separar imaginaçāo e ciência e sem isolar um objeto de outro próximo, lançou as bases para se pensar (e praticar) com aprendizes da ciência (crianças e jovens) os caminhos das ciências da natureza ao mesmo tempo em que privilegiou a natureza com seus incontáveis processos de vida e morte. Entendemos que, em Goethe, encontramos aqueles "elos" perdidos com nosso mundo natural: o espanto com a forma dos seres vivos, o deslumbramento com as cores, os sons, passos para uma estética do belo/ciência, educação ambiental/educaçāo científica.

Nas instituições escolares e de pesquisa talvez tenham sido esquecidas a natureza, as cores e as formas e que os seres vivos são unidades que se relacionam entre si, pois a ciência da natureza, quando se separa da imaginação, passa a ser somente uma reunião de dados secos para nossa educação científica.

Crianças em comunidade de conhecimento: aprendendo ciências

Imaginemos uma escola onde as crianças, independente de suas idades, estejam em salas, laboratórios $\mathrm{e} / \mathrm{ou}$ oficinas trocando conhecimentos 
matemáticos, conhecimentos sobre plantas, bichinhos, elaborando hipóteses acerca do movimento das bolinhas de gude, sombras etc. As cadeiras, evidentemente, não seriam como as de hoje: ordenadas uma atrás da outra, nem as crianças estariam "seriadas" por idade e, menos ainda, os conhecimentos seriam chamados de "conteúdos", em uma seqüência de ciências fragmentadas.

Essa idéia - utopia para a educação - tem sido experienciada por Seymour Papert, lógico-matemático, que escreveu o livro A família conectada. Nessa utopia, a educação, seguramente, não está a serviço de nenhum utilitarismo.

Gual a natureza dessas comunidades? Vivenciar os diferentes conhecimentos a partir de desafios e do pluralismo epistemológico como disse Papert. Ou seja, pensar, falar, resolver, propor soluçōes como nas palavras do matemático Ian Stewart no livro Os números da natureza (1996: 12/17), buscar belezas no meio em que estamos:

Há muita beleza nos indicios da natureza. e todos nós podemos reconhecê-la sem qualquer treino em matemática. (...) Você pode brincar com muitas muito possivelmente com o modo pelo qual a matéria está distribuida por todo o universo.

A exploração de jogos matemáticos com baralhos, jogos de damas, xadrez e de padrões de folhas, flores, frutas e pequenos animais leva-nos à (re)descobertas das ciências e dos cientistas: padrōes numéricos, geométricos (formas), movimentos. As crianças sảo boas observadoras desses padrōes e os redescobrem estabelecendo um vinculo entre a matemática e a natureza. Stewart (idem: 16) chamou nossa atenção para o que ele denominou padrões matemáticos na natureza: 
O amor da natureza pelas listras e manchas se estende ao reino animal, com os tigres e os leopardos, as zebras e as girafas. As formas $e$ os padróes encontrados nos antmais $e$ plantas constituem um solo fértil para os que tèm uma mente matemática. por exemplo, por que muitas conchas formam espirais? Por que as estrelas do mar são dotadas de um conjunto simétrico de braços?

Ao lado desses padrōes, temos o movimento. A locomoção de uma centopéia foi uma fonte de atração e de hipôteses sobre seu harmonioso movimento entre as crianças do Lar Escola em Maringa ${ }^{3}$ nossas atividades de "exploração cientifica" de plantas a animaizinhos em um exercicio próximo ao que chamamos de jogos biológicos.

No periodo de maio a dezembro de 1998, recorremos à idéia de Papert para o trabalho com as crianças: grupos de diferentes idades participaram de jogos matemáticos e de atividades em ciências, no caso, biológicas. Os grupos foram formados por crianças que pertencem à $2^{\mathrm{a}}$ e $3^{\mathrm{a}}$ série do $1^{\circ}$ grau do ciclo formal, com idades entre 7 e 12 anos de idade.

O trabalho de iniciação à matemática teve como fonte de inspiração os estudos piagetianos acerca da gênese de conceitos matemáticos, tais como: número, proporcionalidade, arranjos e probabilidades, que mostram a existência de uma "matemática das crianças". Piaget mostra que nos aproximamos dos conhecimentos por meio de um processo que envolve sucessivas reorganizaçōes, com os raciocinios lógicos precedendo às relações numêricas e às leis métricas. A jornada de aproximação tem como sentido de trânsito

3 Lar Escola da Criança de Maringá - PR é uma Instituição religlosa de Irmãs Murlaldinas que recebe 300 crianças por dia em dois periodos, manhã e tarde, no contra turno escolar. As crianças, de 6 até 13 anos, têm aulas de "reforço" escolar além de atividades como marcenaria, costura, bordado, pintura, música. Nosso laboratório era chamado de Oficina de Ciênclas com attuidades uma vez por semana com dois grupos de 15 crianças durante os anos de 1998 e 1999. 
uma abordagem que se detém, inicialmente, nos aspectos qualitativos (lógicos) para, posteriormente, alcançar os caracteres quantitativos (numéricos ou métricos).

Em seu livro Para onde vai a educação?, Piaget (1980: 17) aponta o culto ao cálculo, à quantificação, como obstáculos para a aprendizagem e imaginação:

É sobretudo possivel - e nós o verificamos em diversos casos que o insucesso escolar em tal ou tal ponto decorra de uma passagem demasiado rápida da estrutura qualitatína dos problemas (por simples raciocínios lógicos, mas sem a introduçāo imediata das relações numéricas $e$ das leis métricas) para a esquematização quantitativa ou matemática (no sentido das equações já elaboradas) usada habitualmente pelo fisico. (...) mesmo no campo da matemática, muitos fracassos escolares se devem àquela passagem muito rápida do qualitativo (lógico) para o quantitativo (numérico).

Cora preocupações dessa natureza, exploramos jogos e situações que requerem avaliação qualitativa de probabilidades. A título de exemplo, vamos apresentar duas situaçōes que apresentamos para as crianças em outubro/98:

Roleta A

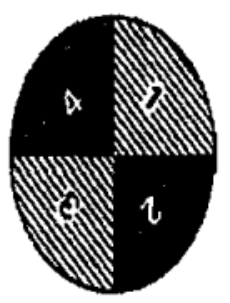

Roleta B

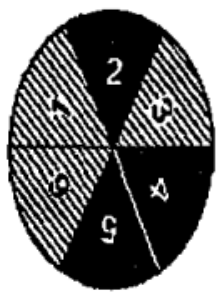

Roleta C

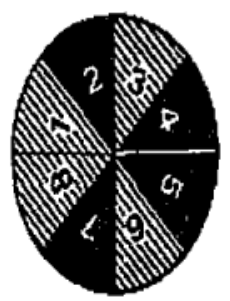

- Quero apostar no número 1, em qual roleta tenho mais chance de ganhar na B ou na $\mathrm{C}$ ?

Algumas respostas que registramos:

Jul (9 anos) 
Aponta o 1 da $\mathrm{B}$ e diz "Aqui tem mais chance porque é maior"

Ant (11 anos)

Aponta a B e diz "Roda menos, os espaços são maiores e tem mais chance".

Alin (9 anos)

Aponta a B e diz "Porque este tem menos números (6), este tem mais (8)"

- Quero apostar que a roleta vai parar na parte escura. Tenho mais chance de acertar apostando na roleta $\mathrm{B}$ ou na roleta $\mathrm{C}$ ?

Ant (11 anos)

“É a mesma coisa, tem 4 contra 4 (C) e 3 contra 3 $(\mathrm{B})^{n}$

Tia (10 anos)

"Acho melhor apostar no $\mathrm{C}$, tem mais espaços pretos"

No terreno das ciências biológicas e da fisica elementar buscamos um caminho para além das denominaçōes biológicas sem significado, ou seja, pensamos em estabelecer relações entre os objetos da natureza e as crianças a partir da observação, da reunião, da classificação, dos desenhos (padrões) etc.

A idéia mais forte podemos dizer que vem da inspiração a partir das reflexões de Stewart (idem: 13):

$O$ ano tem 365 dias - aproximadamente. As pessoas têm duas pernas, os gatos, quatro e os insetos seis, as aranhas, oito. As estrelas-do-mar têm cinco braços (ou dez, 11, e mesmo 17, dependendo da espécie.(...) Um padräo muito curioso ocorre nas pétalas das flores. Em quase todas elas, o número das pétalas é um dos que ocorrem nesta estranha seqüência: $3,5,8,13,21$, $34.55,89$.

Pode ser espantoso, mas $3+5=8,5+8=13$ e, assim por diante. $\hat{E}$ o que chamamos de regularidade matemática. E essa série seqüencial chama-se série de 
Fibonacci, em homenagem a Leonardo Fibonacci, matemático do século XVII. Essa mesma seqüência que sempre estabelece uma razão de 1,6 - ocorre em outros lugares da natureza: nos cones das cicadáceas, nas fileiras das escamas do abacaxi (elas têm 8 fileiras de escamas que se inclinam para a esquerda e 13 para a direita).

Em um dia de novembro/98, quando chegamos para uma "exploração" cientifica com as crianças, elas lutavam entre si, jogando uma pobre centopéia um contra o outro. Esse "objeto" foi cenário de surpreendentes hipóteses. Para elas, a centopéia era um "piolho de cobra". Perguntamos: "Há cobras por aqui?" $\mathrm{E}$ daí, distinguiram-na das cobras porque a centopéia tinha anéis (Silvio, 11 anos). Para Rafael ela tinha 50 patas de cada lado e para Tiago, a "casa" dela não podia ser igual à da vespa, pois esse bichinho não tinha asas e, mesmo se as tivesse, nāo poderia morar em um lugar igual, o corpo era maior.

Esse espirito formulador de perguntas e hipóteses, as crianças já haviam demonstrado em outubro/98, quando Tiago R., Tiago F., Daniele, Israel, William, Alien, Leanderson, Mayara, Donizete e Silvio "cataram" na horta e no jardim da escola mangas, mamão, sempre-vivas, limão, folhas de mamão, camarão (flor), folhas de figo, grama, paus, pedras, pedaços de casa de vespas e de abelhas.

De volta para as mesas, as crianças separaram o material sem que tivéssemos solicitado. Sílvio separou seu material em comestiveis e não comestiveis; Israel separou em folhas com nervuras paralelas e em ramos; Mayara e Tiago separaram as sempre-vivas e formularam a hipótese de que essas flores eram parentas do girassol e do sol. Donizeti e William 
separaram em folhas grandes e pequenas. Alien separou em grupos de folhas, de frutos e de flores.

Lembremo-nos de Goethe: "quanto mais se habituar a pensar, isto é, a comparar o que $\hat{\mathrm{e}}$ semelhante e separar o que não é semelhante" quanto mais nos aproximaremos da ciência. Mais ainda, recordemos Piaget: "a biologia classifica os objetos com os quais trabalha, elucida suas relações (...) por meio das observações dos seres vivos". E, com Ian Stewart, lembremo-nos da idéia de que a natureza "é sutil, simples (...)" e nos deixa pistas para quebrarmos a cabeça como um Sherlock Holmes científico.

Nessa experiência de 1998, tivemos algumas surpresas na primeira abordagem com a comunidade de crianças do Lar Escola: a classificação, a observação e a busca de padronização foram os caminhos das crianças como pequenos cientistas. Valeu gritar em coro com Wagensberg: "Bem vindos, amigos, à imaginação cientifica!"

Referências bibliográficas

BETHELHEIN, Bruno \& ZELAN, Karen. Psicanálise da alfabetização. Porto Alegre: Artes Médicas, 1986.

CITATI, Pietro. Goethe. São Paulo: Cia das Letras, 1996.

GOETHE, Johann W. Ciência e Arte. Tradução de Marcelo Grüel. Universidade de Santa Catarina, 1996, mimeo.

GOODFIELD, June. Um mundo imaginado. Uma histôria de descoberta cientifica. Portugal: Gradiva, s/d.

HUNTLEY, H. E. A divina proporção. Brasillia: Editora Universidade de Brasilia, 1985.

PAPERT, Seymour. A máquina das crianças. Porto Alegre: Artes Médicas, 1996.

PIAGET, Jean. Para onde vai a educação? Rio de janeiro: Livraria José Olympio, 1980. 
PIAGET, Jean. Investigaciones sobre la generalización. Premia Editora, 1984.

STEWART, Ian. Os números da natureza. São Paulo: Rocco, 1996

SAGAN, Carl. O mundo assombrado pelos demônios. São Paulo: Cia das Letras, 1996

SINGH, Simon. O último teorema de Fermat. Rio de Janeiro: Record, 1997.

WAGENSBERG, Jorge. Sobre la imaginación científica. Barcelona: Tusquets, 1990 